\title{
Basic Properties of Pyrolysis Carbon Black of Waste Tyres and Application of Pyrolysis Carbon Black in Transition Layer Rubber of All Steel Radial Tire
}

\section{Qi LIU' ${ }^{1}$, Hui LII ${ }^{1,2}$, Jian LI ${ }^{3}$}

1.Shenzhou Tires in Ningxia, PingLuo, 753400, China

2.China University of Mining and Technology, Beijing 100039,China;3. Key Laboratory of Intelligent Control and Rehabilitation Technology of the Ministry of Civil Affairs, National Research Center for Rehabilitation Technical Aids, Beijing 100176, China

\begin{abstract}
:
The main chemical composition of pyrolysis carbon black of waste tires is $\mathrm{C}, \mathrm{O}, \mathrm{Cu}, \mathrm{Zn}$ and so on. The content of ash and fine powder in pyrolysis carbon black is high, and the $300 \%$ elongation stress is high. The difference between pyrolysis carbon black and furnace black N326, which is commonly used in rubber, is obvious compared with chemical property. The pyrolysis carbon black was used to replace furnace black N326 in the transition layer of all steel load Radial tire rubber through experimental study. It was found that the compression heat generation and dynamic loss (Tan $\delta$ ) of the blend rubber before and after aging were obviously reduced, the elongation at break and resilience increased, while the tensile stress and tear strength decreased by $100 \%$ and $300 \%$, but the hardness and tensile strength changed little before and after aging. According to the latest raw material price calculation, 15 used tire pyrolysis carbon black instead of furnace carbon black N326 used in all steel Radial tire transition layer rubber application, excluding labor costs, electricity and equipment depreciation, a ton of blended rubber saves about $\$ 22.86$ in production costs.
\end{abstract}

Keywords: waste tyre; pyrolysis carbon black; all steel radial truck tire; the transition layer formula; mixing rubber

With the rapid development of automobile industry and road transportation industry, the demand for tires is increasing day by day, which leads to a sharp increase in the quantity of waste tires ${ }^{[1]-[2]}$. It is a very promising project to process waste tires into pyrolyzed carbon black for reuse. Through experimental analysis of pyrolyzed carbon black from waste tires, it is found that its main chemical components are $\mathrm{C}, \mathrm{O}, \mathrm{Cu}, \mathrm{Zn}, \mathrm{S}$ and so on, the ash content is up to $15.0 \%$, and the $300 \%$ tensile stress is up to $7.5 \mathrm{MPA}$. Compared with the furnace carbon black N326 commonly used in rubber, the chemical property difference is very obvious ${ }^{[3]-[8]}$. The pyrolysis carbon black of waste tires can greatly reduce the production cost without affecting the basic physical and mechanical properties and processing properties of rubber blends.

\section{Experiment}

\subsection{Main raw materials}

Natural rubber :SMR20\#, Malaysia; Carbon black :N326, black cat carbon black co., LTD. Pyrolysis carbon black: environmental protection level, shandong Qingdao qindu industry and trade co., LTD. Composite active zinc oxide: nanometer $\geq 47.0 \%$, fuyang hongli chemical co., LTD. Sulfur accelerator: DZ, shandong shangshun chemical co. LTD.

\subsection{Test formulations}

The formula of transition layer: SMR20\# 100 phr, N326 + Cracked black 58 phr, Zinc oxide 8 phr, Antioxidant RD $1.0 \mathrm{phr}$, Insoluble sulphur $5.0 \mathrm{phr}$, Adhesive RA-65 $5.0 \mathrm{phr}$, Accelerator $1.2 \mathrm{phr}$, other $2.5 \mathrm{phr}$.

Experimental Protocol (N326/ Pyrolysis carbon black): 1\#Scheme: 58 / 0 phr; 2\#Scheme: 48 / 10 phr; 3\#Scheme: 43 / 15 phr; 4\#Scheme: 38 / 20 phr.

\subsection{Major equipment and instruments}

Qingdao xianrui mechanical \& electrical company: XK-160 type mill, XLB-800 type plate vulcanizing machine; Kobe steel, Japan: BB-2 miniature mixer; American alpha: rubber processing analyzer RPA2000, meney viscometer MV2000, rotor-free sulfur transformer MD2000; Brabender company, Germany: carbon black oil absorption meter type C; American strong company: electronic tension machine; Beijing jingwei gaobo co., LTD. ; special surface area tester for carbon black; Oxford, UK: INCA-Energy 
X-ray Spectrometer; Scanning electron microscope, Japan: JSM-6700F.

\subsection{Sample preparation}

The samples were mixed with a closed rubber mixer and an open rubber mixer. First, the samples were mixed in a closed rubber mixer (with a rotating speed of $60 \mathrm{r} \bullet \mathrm{min}^{-1}$ ). The order of feeding was as follows: raw rubber $\rightarrow$ medicine $\rightarrow$ carbon black $\rightarrow$ rubber drainage (with an interval of 40 s, rubber drainage at $140^{\circ} \mathrm{C}$ or $260 \mathrm{~s}$ ). The curing agent (roller temperature: $45 \pm 5^{\circ} \mathrm{C}$ ) was added to the open rubber refining machine, the medicine was completely eaten, the thin pass was taken out 8 times, the sample was left in place for 8 hours, and the vulcanization was carried out on the flat curing machine (curing condition: $151^{\circ} \mathrm{C} * 30 \mathrm{~min}$ ).

\subsection{Performance testing}

All properties of rubber are tested in accordance with national or enterprise standards.

\section{Outcomes and discussions}

\subsection{Comparison of the Chemical Properties of Carbon Black}

The comparison of pyrolysis and furnace black chemical property $\mathrm{N} 326$ is shown in Table 1 . The test results show that. The iodine value and specific surface area of nitrogen adsorption of pyrolysis carbon black NSA (multi-point) were obviously lower than that of furnace black N326. The oil absorption values of pyrolysis carbon black DBP, compressed DBP and 300\% elongation stress were higher than those of furnace carbon black N326. The ash content of the pyrolyzed carbon black is obviously higher at $825^{\circ} \mathrm{C}$ because it contains not only elements such as $\mathrm{C}, \mathrm{O}$, but also metallic elements such as $\mathrm{Cu}$ and $\mathrm{Zn}$.

Table 1. Comparison of Chemical Properties of Different Carboniferous Black

\begin{tabular}{lcc}
\hline Project & Carbon Black N326 & Pyrolysis carbon black \\
\hline Iodine absorption value g/kg & 86.68 & 46.00 \\
DBP Absorption value $10^{-5} \mathrm{~m}^{3} / \mathrm{kg}$ & 72.00 & 86.00 \\
Compressed DBP Absorption & & \\
Value $10^{-5} \mathrm{~m}^{3} / \mathrm{kg}$ & 70.10 & 75.00 \\
Heating reduction $125^{\circ} \mathrm{C} \%$ & 0.53 & 1.30 \\
Ash content $825^{\circ} \mathrm{C} \%$ & 0.33 & 15.00 \\
Sieve residue $45 \mu \mathrm{m} \%$ & 0.05 & 0.50 \\
$300 \%$ constant tensile stress $\mathrm{Mpa}$ & -2.90 & 7.50 \\
Nitrogen adsorption ratio surface & & \\
Area NSA (multiple spot) $10^{3} \mathrm{~m}^{2} / \mathrm{kg}$ & 76.68 & 54.00 \\
Fine powder content \% & 4.48 & 130.60 \\
\hline
\end{tabular}

As can be seen from figure 1, In addition to c element, the main components of cracked carbon black are O, SI, $\mathrm{S}$ nonmetal and Four metallic elements, $\mathrm{Zn}, \mathrm{Cu}, \mathrm{Ni}, \mathrm{AI}$, The mass fractions of each element was $85.84 \% \mathrm{C}, 4.48 \%$ O, $0.12 \% \mathrm{Si}, 2.18 \% \mathrm{~S}, 6.54 \% \mathrm{Zn}, 0.38 \% \mathrm{Cu}, 0.36 \% \mathrm{Ni}$ and $0.10 \%$ AI. The $\mathrm{Zn}$ element is mainly from zinc oxide, and the $\mathrm{S}$ element is mainly from sulfur.

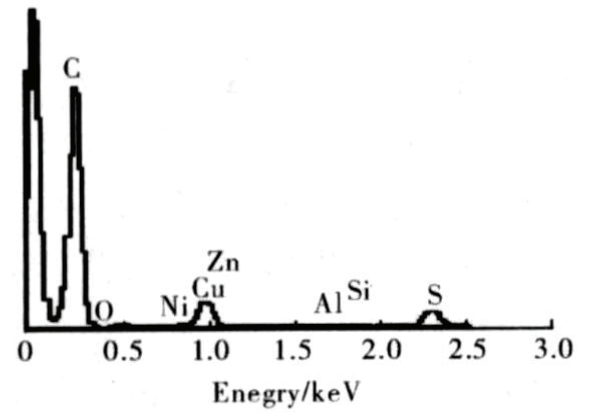

Figure 1. X-ray energy spectrum of pyrolysis carbon black

The SEM images of pyrolysis carbon black of waste tires and furnace carbon black N326(as shown in figure 2) show that the aggregate size of pyrolysis carbon black is obviously larger than that of furnace carbon black N326, and the size of pyrolysis carbon black is about $10 \mathrm{~m}$, the aggregate size of furnace black N326 is about $1.5 \mathrm{~m}$. In comparison, the size distribution of N326 particles is narrow, and the particles of both pyrolysis and furnace carbon black N326 are spherical, but the particles of pyrolysis black are smaller and more closely arranged.
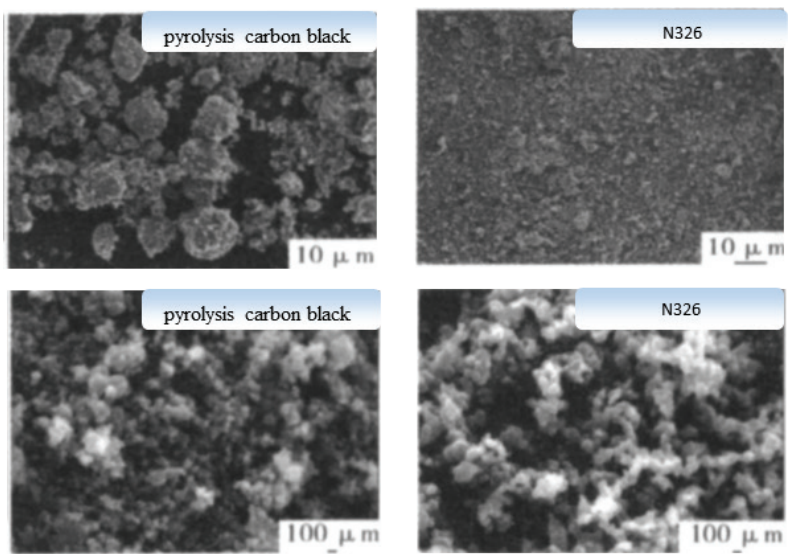

Figure 2. EM SCAN (pyrolysis carbon black, N326 carbon black) 


\subsection{Performance comparison of blended rubber}

\subsubsection{Comparison of sulfur mutators}

Table 2 sulfur changed instrument test results show that with pyrolysis carbon black in full steel loading meridian tyre transition layer rubber, with the increase of adding amount of mixing rubber Mooney viscosity increasing, the scorch time and T5 (or t10) in pyrolysis carbon black and other attachments instead of furnace black N326 increased to 15 \# (scheme 3) when the longest, largest torque $\mathrm{MH}$ decrease is sulfide 3 \# scheme for the longest time.

2.2.2 Physical performance comparison

The physical and mechanical performance test results of mixed rubber are shown in table 3 . With the increase of the number of carbon black added to the rubber in the transition layer of all-steel load radial tire, the constant elongation stress and tear strength of mixed rubber significantly decreased by $100 \%$ and $300 \%$. Elongation at break and rebound increase before and after aging; The change of hardness and tensile strength before and after aging is not obvious. With the increase of the amount of pyrolysis carbon black, the compression heat of mixed rubber decreased first and then increased. When pyrolysis carbon black was added to 15 parts (such as scheme $3 \#$ ), the compression heat of mixed rubber was the lowest. The results show that the dynamic loss factor (Tan $\delta$ ) decreases with the increase of the amount of carbon black added at the same scanning temperature, and the dynamic loss factor Tan decreases with the increase of scanning temperature, the dynamic loss factor (Tan $\delta$ ) of rubber blends with the same amount of pyrolysis carbon black was decreased.

Table 2. Comparison of sulfur mutators for mixed rubber under test scheme

\begin{tabular}{lcccc}
\hline \multirow{2}{*}{ Project } & \multicolumn{4}{c}{ Formula number } \\
\cline { 2 - 4 } & 1\# Scheme & 2\# Scheme & 3\# Scheme & 4\# Scheme \\
\hline Menny viscosity $\left[\mathrm{ML}(1+4) 100^{\circ} \mathrm{C}\right]$ & 62 & 64 & 63 & 65 \\
Mengniao t5 $\left(130^{\circ} \mathrm{C}\right) / \mathrm{min}$ & $17: 45$ & $18: 12$ & $18: 40$ & $18: 36$ \\
Sulfur meter $\left(151^{\circ} \mathrm{C}^{*} 60 \mathrm{~min}\right)$ & & & \\
$\mathrm{ML} /(\mathrm{dN} \cdot \mathrm{m})$ & 2.14 & 2.24 & 2.19 & 2.10 \\
$\mathrm{MH} /(\mathrm{dN} \cdot \mathrm{m})$ & 30.04 & 27.87 & 25.89 & 25.13 \\
$\mathrm{t} 10 / \mathrm{m}: \mathrm{s}$ & $04: 23$ & $05: 00$ & $05: 17$ & $05: 12$ \\
$\mathrm{t} 30 / \mathrm{m}: \mathrm{s}$ & $06: 47$ & $07: 31$ & $07: 55$ & $07: 56$ \\
$\mathrm{t} 60 / \mathrm{m}: \mathrm{s}$ & $10: 40$ & $11: 16$ & $11: 49$ & $11: 52$ \\
$\mathrm{t} 90 / \mathrm{m}: \mathrm{s}$ & $19: 35$ & $19: 35$ & $20: 19$ & $20: 06$ \\
\hline
\end{tabular}

Table 3. Comparison of Physical Properties of Mixed Rubber under Test Scheme

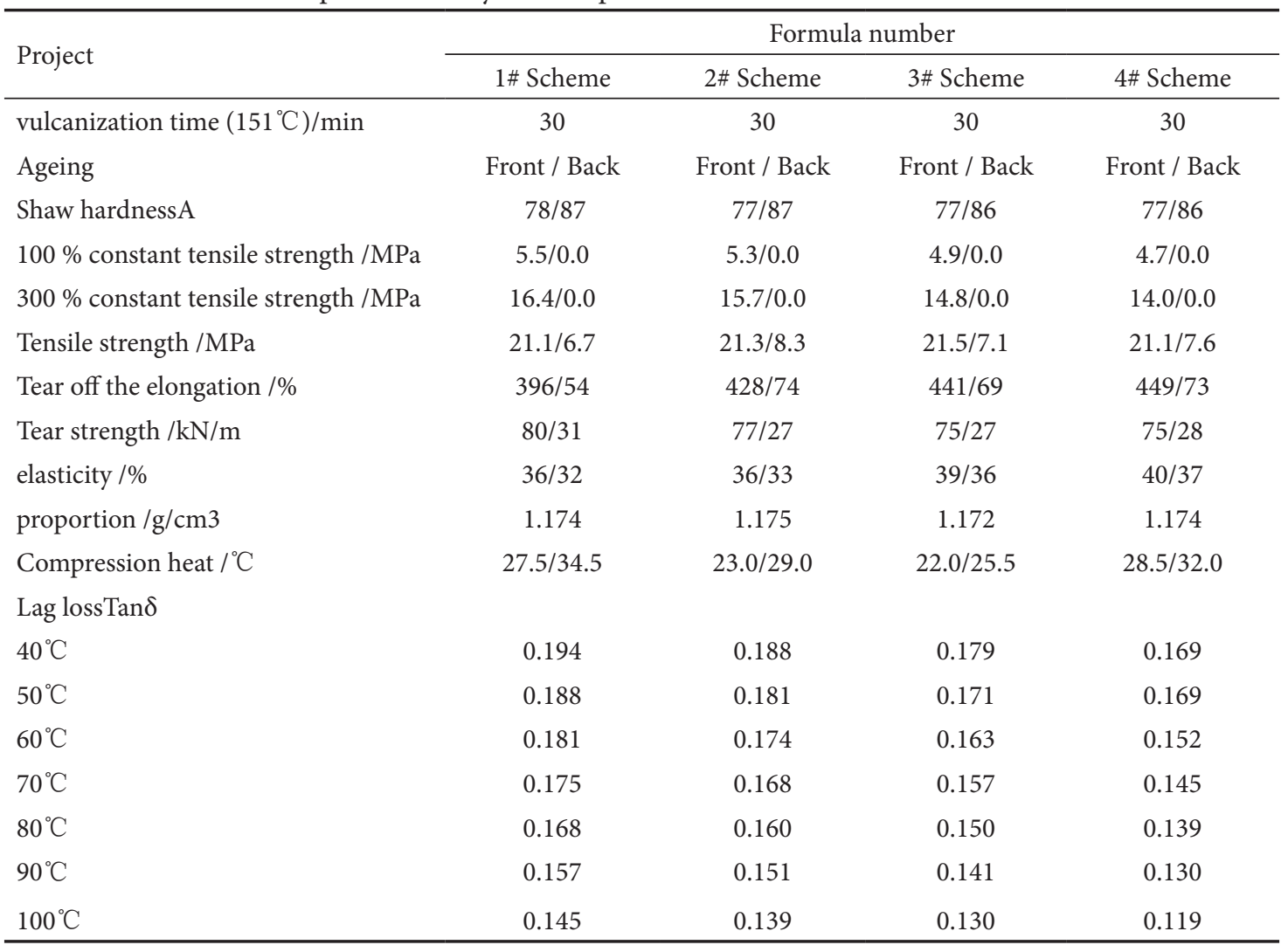


Remarks: 1) Compression heat generation: stroke 4.45 $\mathrm{mm}$; Load 1MPa; Temperature $55{ }^{\circ} \mathrm{C}$. 2) Aging conditions: $100{ }^{\circ} \mathrm{C} * 48 \mathrm{~h}$.

\subsection{Costing of mixed rubber}

According to the latest raw material price accounting (as shown in Table 4), in all-steel load-bearing Radial tire rubber
According to the latest raw material price accounting (as shown in table 4), when the carbon black of waste tires is used to replace furnace carbon black N326 added to 15 parts in the transition layer rubber of all-steel load Radial tire, without taking into account labor costs, electricity charges and depreciation of equipment, each ton of blended rubber can save about us $\$ 22.86$ in production costs.

Table 4. Latest price and cost accounting of raw materials

\begin{tabular}{|c|c|c|c|c|c|c|}
\hline NO. & material & $\begin{array}{l}\text { Unit price } \\
\text { (USD / kg) }\end{array}$ & $\begin{array}{l}\text { Experimental } \\
\text { formulation }\end{array}$ & $\begin{array}{l}\text { Unit price of } \\
\text { experimental } \\
\text { formula }\end{array}$ & Current formulation & $\begin{array}{l}\text { Unit price of } \\
\text { current formula }\end{array}$ \\
\hline 1 & SMR20\# & 1.25 & 100.00 & 125.00 & 100.00 & 125.00 \\
\hline 2 & N326 & 0.87 & 43.00 & 37.30 & 58.00 & 50.32 \\
\hline 3 & Pyrolyss black & 0.63 & 15.00 & 9.38 & 0.00 & 0.00 \\
\hline 4 & $\mathrm{ZnO}$ & 2.07 & 8.00 & 16.54 & 8.00 & 16.54 \\
\hline 5 & Antiager RD & 2.14 & 1.00 & 2.14 & 1.00 & 2.14 \\
\hline 6 & Antiager 4020 & 2.35 & 0.50 & 1.18 & 0.50 & 1.18 \\
\hline 7 & Homogenizing agent & 0.70 & 0.50 & 0.35 & 0.50 & 0.35 \\
\hline 8 & Cobalt decanoate & 14.00 & 0.80 & 11.20 & 0.80 & 11.20 \\
\hline 9 & Imports HD OT20 & 2.27 & 3.00 & 6.80 & 3.00 & 6.80 \\
\hline 10 & China HD OT20 & 1.71 & 2.00 & 3.42 & 2.00 & 3.42 \\
\hline 11 & RA-65 & 1.37 & 5.00 & 6.86 & 5.00 & 6.86 \\
\hline 12 & $\mathrm{DZ}$ & 5.08 & 1.20 & 6.09 & 1.20 & 6.09 \\
\hline 13 & CTP & 4.38 & 0.20 & 0.88 & 0.20 & 0.88 \\
\hline \multicolumn{3}{|c|}{ Total } & 180.20 & 227.13 & 180.20 & 230.77 \\
\hline \multicolumn{3}{|c|}{ Mixed rubber USD/kg } & \multicolumn{2}{|c|}{1.26} & \multicolumn{2}{|c|}{1.28} \\
\hline \multicolumn{3}{|c|}{ Price differential USD/t } & \multicolumn{4}{|c|}{22.86} \\
\hline
\end{tabular}

\section{Conclusion}

1) the chemical properties of pyrolysis carbon black and furnace carbon black N326 are significantly different. Pyrolysis carbon black not only contains C, S, O and other elements, but also contains $\mathrm{Cu}, \mathrm{Zn}$ and other metal elements; The particle size and structure of pyrolysis carbon black are different from that of furnace carbon black N326.

2) transition layer in full steel loading meridian tyre pyrolysis carbon black used in rubber, when pyrolysis carbon black added to 15, mixing rubber compression born before and after aging heat and dynamic loss were significantly lower, higher elongation at failure, the springback, stretch stress and tear strength decreased, other physical properties such as hardness, tensile strength did not change significantly relative.

3) The addition of pyrolysis carbon black from used tyres to the transition layer rubber of Radial tire can save about us $\$ 22.86$ per ton of blended rubber when equal parts of carbon black are added to 15 parts of carbon black in place of furnace method.

\section{References}

[1] zhao wen-jin, liu jia, new progress in pyrolysis recycling of waste tires (2009), rubber technology and equipment 36 (7) : 9-15
[2] cheng yuan, a new bright spot of waste tire recycling -negative pressure cracking (2008), proceedings of forum on recycling of waste tire resources in China, 2008.11

[3] Shen bo-xiong, Lu feng, Liu ting, modification of carbon black cracking of waste tires (2009), Chemical Journal 60(9): 2327-2331

[4] Du ai-hua, Su chang-yan, Chen Hong, Leng hai-yan, Waste Tire Rift Carbon Black Basic Properties and Its Application in Butyrene Rubber (2009), Synthetic Rubber Industry 31(6): 446-449

[5] Xiao guo-liang, Peng xiao-qin, Gai guo-sheng, ultrafine crushing and surface modification of carbon black cracking of waste tires and application in NR (2004). Rubber Industry 51(2): 78-82

[6] Peng xiao-qin, Xiao guo-liang, deep processing and application of carbon black cracking of waste tires (2004), Polymer Materials Science and Engineering 20(4): 142-145

[7] guo ying-chen, qiao zhan-ping, waste rubber preparation of fuel oil and carbon black (2001), environmental pollution and prevention $28(2): 82-83$

[8] liu bao-qing, jiang jia-ling, liu xiao-long, vertical cracking tower for recycling carbon black and fuel oil from waste tires (2004), synthetic rubber industry 27 (1) : 17-20 